\title{
DON'T NEGATE IMPERATIVES! IMPERATIVES AND THE SEMANTICS OF NEGATIVE MARKERS
}

\author{
Hedde Zeijlstra \\ University of Tübingen
}

hedde.zeijlstra@uni-tuebingen.de

\begin{abstract}
Languages cross-linguistically differ with respect to whether they accept or ban True Negative Imperatives (TNIs). In this paper I show that this ban follows from three generally accepted assumptions: (i) the fact that the operator that encodes the illocutionary force of an imperative universally takes scope from $\mathrm{C}^{\circ}$; (ii) the fact that this operator may not be operated on by a negative operator and (iii) the Head Movement Constraint (an instance of Relativized Minimality). In my paper I argue that languages differ too with respect to both the syntactic status (head/phrasal) and the semantic value (negative/non-negative) of their negative markers. Given these difference across languages and the analysis of TNIs based on the three above mentioned assumptions, two typological generalisations can be predicted: (i) every language with an overt negative marker $\mathrm{X}^{\circ}$ that is semantically negative bans TNIs; and (ii) every language that bans TNIs exhibits an overt negative marker $\mathrm{X}^{\circ}$. I demonstrate in my paper that both typological predictions are born out.
\end{abstract}

\section{Introduction}

This paper is about the fact that not every language accepts so-called True Negative Imperatives (TNIs). ${ }^{1}$ TNIs are exemplified in (1) and (2) for Dutch and Polish respectively. In Dutch, in main clauses the finite verb precedes the negative marker niet. In imperative clauses the negation can also follow the finite imperative verb without yielding ungrammaticality. Polish also accepts TNIs: both in regular negative indicative clauses and in imperative clauses, the negative marker nie immediately precedes the finite verb.
a. Jij slaapt niet
You sleep NEG
'You don't sleep'
b. Slaap!
Sleep!
'Sleep'
b. Slaap niet!
Sleep NEG!
'Don't sleep!'

(2) a. (Ty) nie pracujesz

Polish

You NEG work.2SG

'You don't work!'

b. Pracuj!

Work.2SG.IMP

'Work!'

\footnotetext{
${ }^{1}$ Terminology due to Zanuttini (1994)
} 
c. Nie pracuj!

NEG work.2SG.IMP

(TNI)

'Don't work!'

Things are different however in a language like Spanish, as illustrated in (3). In Spanish the negative marker no always occurs in preverbal position. However, if the verb has an imperative form, it may not be combined with this negative marker. Spanish does not allow TNIs. In order to express the illocutionary force of an imperative ${ }^{2}$, the imperative verb must be replaced by a subjunctive. Such constructions are called Surrogate Negative Imperatives (SNIs).
a. Tu no lees
NEG read.2SG
'You don't read'
b. ¡Lee!
Read.2SG.IMP
'Read!'
c. $\quad *_{i N o}$ lee!
NEG read.2SG.IMP
'Don't read'
d. ¡No leas!
NEG read.2SG.SUBJ
'Don't read'

Spanish

(*TNI)

(SNI)

In this paper I address two questions: (i) how can this ban on TNIs in languages such as Spanish be explained? And (ii) how does the observed cross-linguistic variation follow?

The outline of the paper is as follows: in section 2 I discuss three previous analyses of the ban on TNIs. In section 3 I discuss some relevant semantic and syntactic properties of negative markers and in section $4 \mathrm{I}$ demonstrate by means of a survey of different languages that the properties described in section 3 are related to the acceptance of TNIs. In section 5, I present my analysis for all language groups that have been discussed. In section 6, I show that the analysis presented in section 5 makes some correct predictions regarding the development of Negative Concord and the acceptance of TNIs in Romance languages. Finally, Section 7 concludes.

\section{Previous analyses}

\subsection{Rivero (1994), Rivero \& Terzi (1995)}

Rivero (1994) and Rivero \& Terzi (1995) assume that the clausal structure always has the structural relations in (4).

$$
\mathrm{CP}>\mathrm{NegP}>\mathrm{IP}>\mathrm{VP}
$$

Then the difference between Slavic languages (which generally allow TNIs) and Romance languages (that generally disallow them) concerns the position where imperative force is induced in the sentence. This is either IP (expressed by movement of $V_{\text {imp }}$ to $\mathrm{I}^{\circ}$ ) or $\mathrm{CP}$ (expressed by verbal movement to $\mathrm{C}^{\circ}$ ). Now the difference between Slavic and Romance languages falls out immediately: if the $\mathrm{Neg}^{\circ}$ position is filled by an overt element, i.e. by a

\footnotetext{
${ }^{2}$ Negative sentences with the illocutionary force of an imperative are often referred to as prohibitives.
} 
negative marker, then verbal movement from $\mathrm{I}^{\circ}$ to $\mathrm{C}^{\circ}$ is no longer allowed, given the Head Movement Constraint (Travis (1984)). Hence Slavic languages, such as Polish allow TNIs, whereas Romance languages, such as Spanish, where the verb moves to $\mathrm{C}^{\circ}$, do not (see (5)).
a. $\quad\left[\mathrm{NegP}\left[\mathrm{Neg}^{\circ} \mathrm{Nie}\right]\left[\mathrm{IP}\left[\mathrm{I}^{\circ} \operatorname{pracuj}_{[\mathrm{IMP}] \mathrm{i}}\right]\left[\mathrm{VP} \mathrm{t}_{\mathrm{i}}\right]\right]\right]$
NEG work.2SG.IMP
'Don't work!'
b. $\quad *\left[\mathrm{CP}\left[\mathrm{C}^{\circ} \operatorname{Lee}_{[\mathrm{IMP}] \mathrm{i}}\right]\left[\mathrm{NegP}\left[\mathrm{Neg}^{\circ} n o\right]\left[\mathrm{IIP}\left[\mathrm{I}^{\circ} \mathrm{t}_{\mathrm{i}}\right]\left[\mathrm{VP} \mathrm{t}_{\mathrm{i}}\right]\right]\right]\right] \quad$ Spanish NEG read.2SG.IMP
'Don't read!'
Polish

Rivero's and Rivero \& Terzi's analysis faces two serious problems. The first problem is that it is unclear why in Romance languages the negative marker is not allowed to clitisize onto $V_{\text {imp }}$ so that they move together to $\mathrm{C}^{\circ}$ as a unit, a point already addressed by Han (2001). Rizzi (1982) argues that in constructions such as (6), consisting of a participle or an infinitive, the subject occupies a Spec,IP position and the auxiliary moves to $\mathrm{C}^{\circ}$. In case of negation, the negation then joins the verb to move to $\mathrm{C}^{\circ}$. Rizzi refers to these structures as Aux-to-Comp constructions.
a. $\quad\left[\left[\mathrm{C}^{\circ} \text { avendo }\right] \text { Gianni fatto questio }\right]^{3}$ having Gianni done this 'Gianni having done this, ...'
b. [[ $\quad\left[\mathrm{C}^{\circ}\right.$ non avendo] Gianni fatto questio $]$
NEG having Gianni done this
'Gianni having not done this, ...'

If in the cases above non is allowed to attach to $\mathrm{V}_{\text {part }} / \mathrm{V}_{\text {inf }}$, it is unclear why this movement would not be allowed in the case of $\mathrm{V}_{\text {imp. }}{ }^{4}$

The second problem is that in the structure in (5)a the operator that encodes the illocutionary force of an imperative is c-commanded by the negation. It has already been noted by Frege (1892) and Lee (1988) that negation cannot operate on the illocutionary force of the sentence, but only on its propositional content (a negative assertion remains an assertion, a negative question remains a question, and a negative command has to remain a command). Hence, in Rivero and Terzi's analyses for Slavic languages either negation takes scope from too a high position, or the imperative operator takes scope from too a low position.

\subsection{Zanuttini (1997)}

Zanuttini (1997) distinguishes different kinds of negative markers basing herself on a number of Romance dialects (mostly from Northern Italy). She argues that negative head markers $\left(\mathrm{X}^{\circ}\right)$ that can negate a clause by themselves are actually lexically ambiguous between two different lexical items, which are often phonologically identical. For instances she claims that in Italian the negative marker non is lexically ambiguous between non-1, which may occur only in clauses with the illocutionary force of an imperative, and non-2, which may appear in

\footnotetext{
${ }^{3}$ Example taken from Rizzi (1982)

${ }^{4}$ Rivero and Terzi argue that in these cases the $\mathrm{V}_{\text {part/inf }}$ does not raise to $\mathrm{C}^{\circ}$, but to a position lower than $\mathrm{Neg}^{\circ}$ and that the subject is in a position even below. This analysis seems to be contradicted by the fact that (non) avendo may even precede speaker-oriented adverbs such as evidamente ('evidently'), which occupy a position higher than NegP (as pointed out by Cinque (1999) and repeated in Han (2001)).
} 
all other clauses. Furthermore, Zanuttini proposes that non-1 subcategorizes a MoodP, whereas non-2 does not:

$$
\begin{array}{lll}
\text { a. } & {[\mathrm{NegP} \text { non }-1[\mathrm{MoodP} \ldots[\mathrm{VP}]]]} & \text { imperative clauses } \\
\text { b. } & {[\mathrm{NegP} \text { non }-2 \ldots[\mathrm{VP}]]} & \text { other clauses }
\end{array}
$$

The ban on TNIs can now be accounted for as follows. Imperative verbs are often morphologically defective, indicating that they lack a particular [MOOD] feature. As a result, the [MOOD] feature on Mood $^{\circ}$ cannot be checked and the sentence becomes ungrammatical. In other clauses, e.g. indicatives, there is no MoodP selected, and thus the sentence is grammatical, as shown in (8).

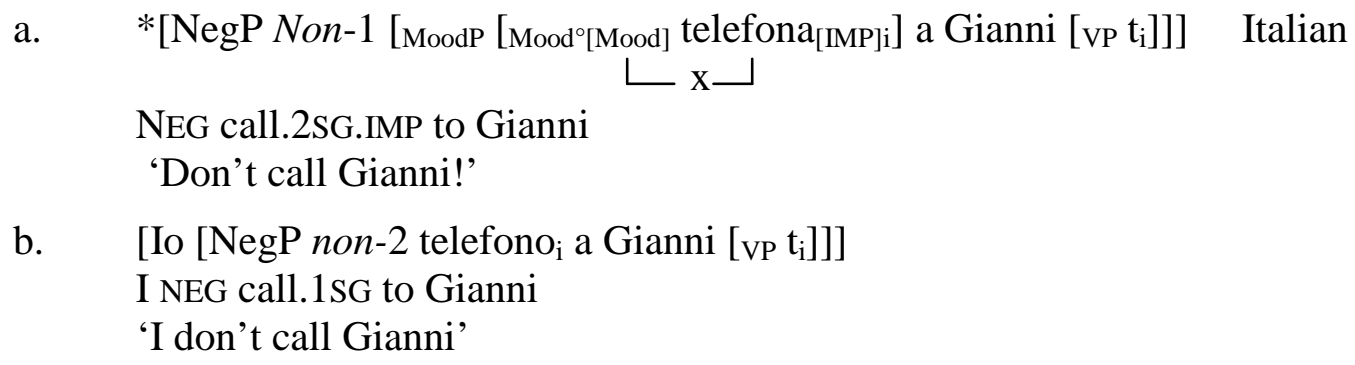

Still, this analysis suffers from two problems. First, the lexical distinction between non- 1 and non-2 seems not well motivated. Although Zanuttini motivates this claim by arguing that languages that have two distinct negative markers are often sensitive to mood distinctions in the verbal paradigm (cf. Sadock \& Zwicky (1985)), it is not clear why languages universally have to exhibit two negative markers. It could even be the case that the motivation for a second negative marker (found in languages such as Hungarian, Albanian and Greek) is because the regular negative marker could not be combined with an imperative. Such a motivation would lead to circularity.

Second, the prediction that this analysis makes is too strong. It is unclear why the analysis does not hold for Slavic languages, such as Polish, which has a negative head marker nie that negates a clause by itself and allows TNIs. Moreover, one may even find Romance varieties, which allow TNIs. Old Italian (9) is an example.

(9) Ni ti tormenta di questo!

Old Italian

NEG yourself torment.2SG.IMP of this

'Don't torment yourself with this!'

\subsection{Han (2001)}

Han (2001) argues that the ban on TNIs does not follow from syntactic requirements that have been violated, but from a semantic violation: the imperative operator (i.e. the operator that encodes the illocutionary force of an imperative, $O p_{\text {IMP }}$ hereafter) may not be in the scope of negation. $O p_{\text {IMP }}$ is realised by moving a feature [IMP] on $\mathrm{V}_{\text {imp }}$ to $\mathrm{C}^{\circ}$. Han takes negation in Romance languages to head a projection somewhere high in the IP domain. Hence, negation head-adjoins first to $\mathrm{V}_{\text {imp }}$, and then as a unit they move further to $\mathrm{C}^{\circ}$. As a result $O p_{\text {IMP }}$ remains in the c-command domain of negation, which violates the constraint that negation may only operate on the propositional content of the clause. The structure (10) is thus ill formed. 




Spanish

Under this analysis, it becomes immediately clear why in languages like Dutch TNIs are allowed. In those languages negation does not form a unit with $\mathrm{V}_{\text {imp }}$ and $\mathrm{V}_{\text {imp }}$ raises across negation to $\mathrm{C}^{\circ}$, as shown in (11).

(11) [CP slaap $\left[\right.$ Imp]i $\left[\mathrm{NegP} / \mathrm{VP}\right.$ niet $\left.\left.\mathrm{t}_{\mathrm{i}}\right]\right]$

Dutch

For Slavic languages Han assumes that $\mathrm{V}_{\text {imp }}$ does not move to $\mathrm{C}^{\circ}$. Consequently, this would mean that $\mathrm{V}_{\text {imp }}$ remains under the scope of negation (as the negative marker is a syntactic head in those languages, $\mathrm{V}_{\text {imp }}$ cannot move across it). However, Han argues that in those cases the feature [IMP] moves out of $\mathrm{V}_{\mathrm{imp}}$ and moves to $\mathrm{C}^{\circ}$. Thus, $O p_{\text {IMP }}$ outscopes negation, as demonstrated in (12) for Polish.

$$
\text { [CP } \left.[\mathrm{IMP}]_{\mathrm{i}}\left[\mathrm{NegP} \text { nie }\left[\mathrm{IP} \text { pracuj }_{\mathrm{i}}\right]\right]\right]
$$

Polish

The fact that Han allows feature movement for the Slavic languages seems to contradict the analysis for Romance languages, since it remains unclear why this feature movement would not be possible in Romance languages. Apart from this problem, Han assumes that the negative marker (in the languages discussed) is always the carrier of semantic negation. In the following section I demonstrate that this is not always the case.

\section{Semantic and syntactic properties of negative markers}

In this section I discuss some semantic properties of negative markers. I present arguments that show that negative markers differ cross-linguistically with respect to their semantic contents. In some languages, such as Spanish and Italian, I argue the negative marker is the phonological realisation of a negative operator. In other languages, such as Polish and Czech, I argue that the negative marker is semantically vacuous, but has a syntactic requirement that it needs to stand in an Agree relation with a negative operator, which may be left phonologically abstract. The section concludes with a few remarks about the syntactic status of negative markers.

\subsection{Strict vs. Non-strict NC languages}

The term Negative Concord (NC) refers to the phenomenon in which two negative elements yield only one semantic negation. The set of NC languages falls apart in two classes: Strict $\mathrm{NC}$ languages and Non-strict NC languages. In Strict NC languages the negative marker may both follow or precede $n$-words ${ }^{5}$ as is demonstrated for Czech in (13). In Non-strict NC languages the negative marker may only precede n-words. An example of a Non-strict NC language is Italian (14).

\footnotetext{
${ }^{5}$ Terminilogy due to Laka (1990), Giannakidou (2002).
} 
(13) Strict NC:

$\begin{array}{lll}\text { a. } & \text { Milan *(ne)vidi nikoho } & \text { Czech } \\ & \text { Milan NEG.saw n-body }\end{array}$

'Milan didn't see anybody'

b. Dnes * (ne)volá nikdo

Today NEG.calls n-body

'Today nobody calls'

c. Dnes nikdo* $\quad$ ne $)$ volá

Today n-body NEG.calls

'Today nobody calls'

(14) Non-strict NC:

a. Gianni *(non) ha telefonato a nessuno Italian

Gianni NEG has called to n-body

'Gianni didn't call anybody'

b. Ieri *(non) ha telefonato nessuno

Yesterday NEG has called n-body

'Yesterday nobody called'

c. $\quad$ Ieri nessuno $(*$ non) ha telefonato (a nessuno)

Yesterday n-body NEG has called to n-body

'Yesterday nobody called anybody'

In Zeijlstra (2004) I argue that NC is a form of multiple Agree (cf. Ura (1996), Hiraiwa (2001, 2005)) between a negative operator that carries an interpretable negative feature [iNEG] and elements that carry an uninterpretable negative feature [uNEG]. Sentence (14)a can thus be analysed as (15), where nessuno's [uNEG] feature is checked against non's [iNEG] feature. ${ }^{6}$

$$
\text { [TP Gianni }\left[{ }_{\mathrm{NegP}} \text { non }_{[\mathrm{NNEG}]} \text { ha telefonato a nessuno }[\mathrm{H \textrm {NEG } ]}]\right]
$$

Given the assumption that $\mathrm{n}$-words are analysed as semantically non-negative indefinites that carry a feature [uNEG] (cf. Ladusaw (1992), Brown (1999), Zeijlstra (2004)), it follows that the negative operator must c-command them in order to yield the correct readings. Consequently, it means that if the negative marker carries a feature [iNEG] no n-word is allowed to precede it (and still yield an NC reading).

However, in Strict NC languages such as Czech, the negative marker may be preceded by an $\mathrm{n}$-word. Consequently, this negative marker cannot be the phonological realisation of the negative operator. It then follows that the negative marker itself carries [uNEG] and that it has its [uNEG] feature checked by an abstract negative operator $O p_{\neg}$, as shown in (16). ${ }^{7}$

$$
\begin{aligned}
& \text { Dnes } O p_{\neg[\mathrm{iNEG}]} n i k d o_{[\mathrm{uNEG}]} n e \text { volá }{ }_{\mathrm{uNEG}]} \\
& \text { Today n-body NEG.calls } \\
& \text { 'Today nobody calls'. }
\end{aligned}
$$

The [uNEG]/[iNEG] distinction exactly explains the Strict NC vs. Non-strict NC pattern that one finds amongst $\mathrm{NC}$ languages. Thus I argue that negative markers in Non-strict NC

\footnotetext{
${ }^{6}$ Note that here a feature checking mechanism is adopted in which checking may take place between a higher interpretable and a lower uninterpretable feature (cf. Adger (2003))

${ }^{7}$ Note that this analysis requires that an abstract $O p_{\neg}$ is also available in Non-strict NC languages, for instance in constructions such as (14)a.
} 
languages, like Italian non and Spanish no, carry a feature [iNEG], whereas negative markers in Strict NC languages, such as Czech ne and Polish nie, carry a feature [uNEG].

\subsection{Further evidence}

I now present some further evidence for the assumption that the difference between Strict and Non-strict NC languages reduces to the semantic value of their negative markers. First it can be shown that negation behaves differently in Strict and Non-strict NC languages with respect to the scope of quantifying DPs. This is shown in (17). Although Czech moc ('much') dominates the negative marker, it is outscoped by negation. This reading is however not obtained in a similar construction in Italian, where molto ('much') remains in the scope of negation. This is a further indication that Italian non, contrary to Czech $n e$, is a phonological realisation of $O p_{\neg}$.

$$
\begin{aligned}
& \text { a. Milan moc nejedl } \\
& \text { Czech } \\
& \text { Milan much NEG.eat.PERF } \\
& \neg \text { > much: 'Milan hasn't eaten much' } \\
& \text { *much }>\neg \text { : 'There is much that Milan didn't eat' } \\
& \text { Much NEG has eaten Gianni }
\end{aligned}
$$

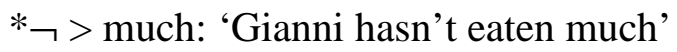

$$
\begin{aligned}
& \text { much > ᄀ: 'There is much that Gianni didn't eat' }
\end{aligned}
$$

Second, in some Strict NC languages the negative marker may be left out if it is preceded by an n-word, something to be expected on functional grounds if the negative marker carries [uNEG] (if an n-word precedes it, the negative marker is no longer needed as a scope marker). This is for instance the case in Greek (a Strict NC language) with oute kan ('NPI-even'). If oute kan precedes the negative marker dhen, the latter may be left out. If it follows dhen, dhen may not be removed (cf. Giannakidou (2005)). This forms an argument that Greek dhen is in fact not semantically negative. As Greek is a Strict NC language, this confirms the assumption that in Strict NC languages the negative marker carries [uNEG].

$$
\begin{aligned}
& \text { a. O Jannis *(dhen) dhiavase oute kan tis Sindaktikes Dhomes } \\
& \text { The Jannis neg reads even the Syntactic Structures } \\
& \text { 'Jannis doesn't read even Syntactic Structures' } \\
& \text { b. Oute kan ti Maria (dhen) proskalese o pritanis } \\
& \text { Even Maria NEG invite the dean } \\
& \text { 'Not even Maria did the dean invite' }
\end{aligned}
$$

Finally, the semantic emptiness of negative markers may solve a problem put forward by Watanabe (2005) against Giannakidou's (2000) analysis of fragmentary answers. Giannakidou $(2000,2002)$ argues that n-words in Greek are semantically non-negative. Hence, she has to account for the fact that n-words in fragmentary answers like in (19)a yield a reading that includes a negation. She argues that this negation, expressed by dhen, is deleted under ellipsis. Hence the assumption that n-words are semantically non-negative can be maintained. Watanabe (2005) argues that this analysis violates the condition that ellipsis may only take place under semantic identity (cf. Merchant's (2001a) notion of e-GIVENness). However, as the question does not contain a negation, it may not license ellipsis of the negative marker dhen. If on the other hand, dhen is semantically non-negative, the identity condition is met again. The abstract negative operator then induces the negation in the answer. Note that in Non-strict NC languages the negative marker never follows an n-word, and therefore no negative marker can be deleted under ellipsis in the first place. 
(19)
a.
Q: Ti ides?
What saw.2SG?
'What did you see?'
b. Q: ¿A quién viste?
What saw.2sG?
'What did you see?'

A: $\left[O p_{\neg}[\right.$ TIPOTA [then ida $\left.\left.]\right]\right]$ Greek

$\mathrm{N}$-thing [NEG saw.1SG]

'Nothing!'

A: $\left[O p_{\neg}[\right.$ A nadie [vió] $\left.]\right]$

N-thing [saw.1SG]

'Nothing!'

\subsection{A few words on syntax}

Finally, a few words on the syntactic status of negative markers need to be said. All three analyses that have been discussed in section 2, as well as my own analysis that I present in section 5, rely crucially on the distinction between negative markers that are syntactic heads $\left(\mathrm{X}^{\circ}\right)$ and those that have phrasal status (XP). I follow the standard analysis (Haegeman (1995), Zanuttini (1997, 2001), Merchant (2001b), Zeijlstra (2004) amongst many others) that negative adverbs (such as Dutch niet, German nicht, French pas) are XPs, whereas weak or strong preverbal negative markers as well as affixal negative markers have $\mathrm{X}^{\circ}$ status (Italian non, Spanish no, Polish nie, Czech ne, Greek dhen, French ne). Hence negative markers can be distinguished in two respects, each with two possible values: they have either $\mathrm{X}^{\circ}$ or $\mathrm{XP}$ status and they have either a value [iNEG] or [uNEG]. ${ }^{8}$

\section{Typological generalisations}

Based on the notions discussed above, a number of languages have been investigated for the syntactic status of their negative markers, and their semantic value. Moreover it has been investigated whether these languages allow TNIs or not. The results are shown in (20) below.

(20) Language sample

\begin{tabular}{|c|c|c|c|c|}
\hline Class: & Language: & Neg. marker: $X^{\circ}$ & Neg. marker: [iNEG] & TNIs allowed \\
\hline \multirow[t]{3}{*}{ I } & Spanish & $\sqrt{ }$ & $\sqrt{ }$ & $*$ \\
\hline & Italian & $\sqrt{ }$ & $\sqrt{ }$ & $*$ \\
\hline & Portuguese & $\sqrt{ }$ & $\sqrt{ }$ & * \\
\hline \multirow[t]{4}{*}{ II } & Czech & $\sqrt{ }$ & * & $\sqrt{ }$ \\
\hline & Polish & $\sqrt{ }$ & $*$ & $\sqrt{ }$ \\
\hline & Bulgarian & $\sqrt{ }$ & $*$ & $\sqrt{ }$ \\
\hline & Serbo-Croatian & $\sqrt{ }$ & $*$ & $\sqrt{ }$ \\
\hline \multirow[t]{4}{*}{ III } & Greek & $\sqrt{ }$ & * & * \\
\hline & Romanian & $\sqrt{ }$ & * & * \\
\hline & Hebrew & $\sqrt{ }$ & * & $*$ \\
\hline & Hungarian & $\sqrt{ }$ & $*$ & $*$ \\
\hline \multirow[t]{4}{*}{ IV } & Dutch & $*$ & $\sqrt{ }$ & $\sqrt{ }$ \\
\hline & German & $*$ & $\sqrt{ }$ & $\sqrt{ }$ \\
\hline & Norwegian & $*$ & $\sqrt{ }$ & $\sqrt{ }$ \\
\hline & Swedish & $*$ & $\sqrt{ }$ & $\sqrt{ }$ \\
\hline \multirow[t]{3}{*}{$\mathrm{V}$} & Bavarian & $*$ & $*$ & $\sqrt{ }$ \\
\hline & Yiddish & $*$ & $*$ & $\sqrt{ }$ \\
\hline & Quebecois & $*$ & $*$ & $\sqrt{ }$ \\
\hline
\end{tabular}

${ }^{8}$ In Zeijlstra (2006), it is argued that in Non-strict NC languages negative markers do not have a formal feature [iNEG], but a semantic feature [NEG]. However, as the interpretation of an element carrying [iNEG] is identical to the interpretation of an element carrying [NEG], I disregard this distinction in this paper, as nothing crucial in this analysis hinges on it. 
Based on (20) the two following typological generalisations can be drawn:

(21) G1: Every language with an overt negative marker $\mathrm{X}^{\circ}$ that carries [iNEG] bans TNIs.

G2: Every language that bans TNIs exhibits an overt negative marker $\mathrm{X}^{\circ}$.

These typological generalisations indicate that both the semantic value of the negative marker and its syntactic status play a role in determining whether and why a language bans TNIs. G2 has already been observed by Zanuttini (1997), G1 is to my knowledge a novel observation. In the next section I present an analysis that is based on these notions.

\section{Analysis}

I argue that both the ban on TNIs and its cross-linguistic distribution can be explained on the basis of the following three well-motivated assumptions. First, I assume that $O p_{\text {IMP }}$ must take scope from $C^{\circ}$, a standard analysis in the syntax of imperatives (cf. Zanuttini (1997)). Second, I adopt he classical observation that operators that encode illocutionary force may not be operated on by a (semantic) negation. In this respect, the analysis presented here reflects Han's analysis. Third, I adopt the HMC (Travis' (1984)), an instance of relativized minimality (cf. Rizzi (1989)). Now I demonstrate how for each combination of $\pm \mathrm{X}^{\circ}, \pm[\mathrm{iNEG}]$ the correct results are predicted.

\subsection{Class I languages}

The first class of languages consists of languages that exhibit a negative marker $\mathrm{X}^{\circ}$, which carries an [iNEG] feature. To these languages Han's analysis applies and $V_{\text {imp }}$ must raise to $\mathrm{C}^{\circ}$. As the negative marker $\mathrm{Neg}^{\circ}$ must be attached to $\mathrm{V}^{\circ}$, this negative marker c-commands [IMP], and given the syntactic head status of the negative marker, $\mathrm{V}_{\text {imp }}$ cannot escape out of this unit. This is illustrated for Spanish in (22)a. If, however, the imperative verb is replaced by a subjunctive, nothing leads to ungrammaticality, since the subjunctive does not carry along a feature that encodes illocutionary force, and thus it may be c-commanded by the negation (see (22)b). Obviously, this does not yield the semantics of a prohibitive. However, I assume, following Han, that the prohibitive reading is enforced through pragmatic inference. The language needs to fill the functional gap and uses the non-imperative construction with the subjunctive as a replacement. The SNI does not yield the reading of a prohibitive, but is then used as one. ${ }^{9}$
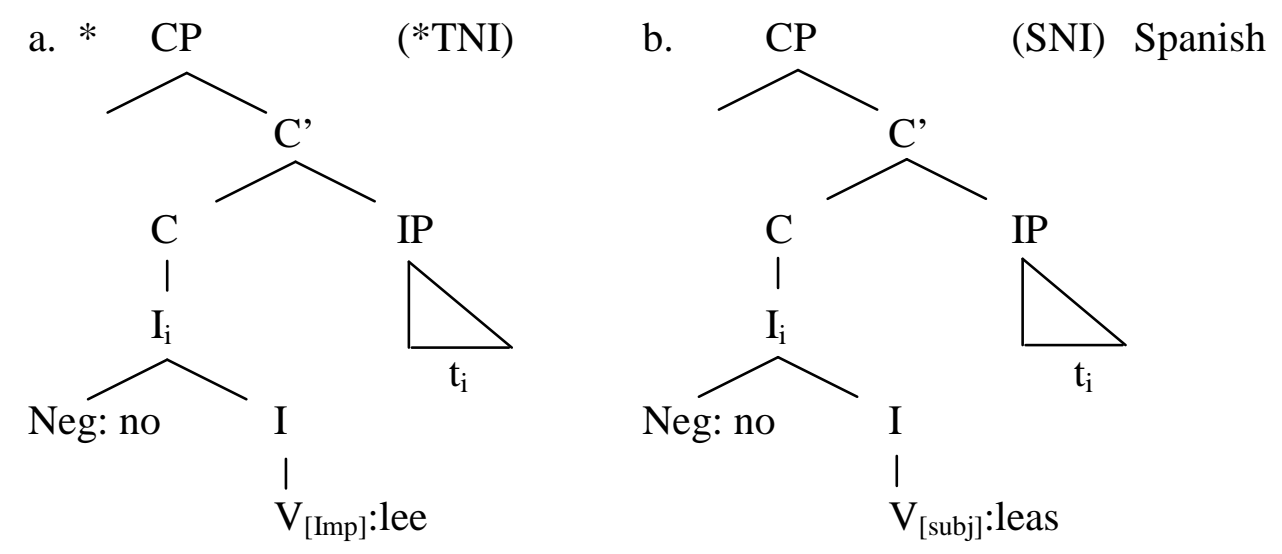

\footnotetext{
${ }^{9}$ Han (2001) suggests that the fact that the subjunctive encodes an irrealis, plays a role in the imperative interpretation. This is however contradicted by the fact that (for instance) an indicative can adopt this function as well (Italian plural SNIs exhibit an indicative).
} 
Note that the first typological generalisation (G1) immediately follows: since the negative head adjoins to $\mathrm{V}_{\text {imp }}$ and $\mathrm{V}_{\text {imp }}$ must raise to $\mathrm{C}^{\circ}, O p_{\text {IMP }}$ cannot avoid being outscoped by negation. Thus every language with an overt negative marker $\mathrm{X}^{\circ}$ that carryies [iNEG] bans TNIs.

\subsection{Class II languages}

Languages that have negative markers $\mathrm{X}^{\circ}$ which carry [uNEG] at their disposal differ with respect to the ban on TNIs. Czech, Polish, Bulgarian and Serbo-Croation for instance accept TNIs, whereas Romanian, Hungarian, Greek and Hebrew disallow them. In this subsection I discuss the first kind of languages.

In Slavic languages, such as Czech, Polish, Bulgarian and Serbo-Croation, the negative marker is always in preverbal position. Slavic languages however differ with respect to the phonological strength of the negative marker. Polish nie is phonologically strong and can be said to be base-generated in its own position $\mathrm{Neg}^{\circ}$ that c-commands VP. Czech $n e$ is weaker than Polish nie and it is thus unclear whether ne originated in $\mathrm{Neg}^{\circ}$ or has been basegenerated as a head adjunction onto $\mathrm{V}$. In both cases, these negative markers are semantically non-negative and negation is thus induced from $O p_{\neg}$. I assume as Zeijlstra (2004) that this $O p_{\neg}$ occupies a Spec,NegP position. The clausal structure therefore does not block TNIs. In Polish $\mathrm{V}_{\text {imp }}$ moves to $\mathrm{Neg}^{\circ}$, attaches to nie and as a unit [Neg nie- $\left.\mathrm{V}_{\text {imp }}\right]$ moves along to $\mathrm{C}^{\circ} . O p_{\neg}$ remains in situ in Spec,NegP and $O p_{\text {IMP }}$ takes scope from $\mathrm{C}^{\circ}$. In Czech the complex verbal unit $\left[\mathrm{v} n e-\mathrm{V}_{\mathrm{imp}}\right]$ moves through $\mathrm{Neg}^{\circ}$ (and all other intermediate head positions) to $\mathrm{C}^{\circ}$, from where $O p_{\text {IMP }}$ takes scope. $O p_{\neg}$ is located in Spec,NegP. Thus, both in Polish and Czech the scopal condition $O p_{\text {IMP }}>O p_{\neg}$ is met. This is illustrated below in for Polish in (23) and for Czech in (24).

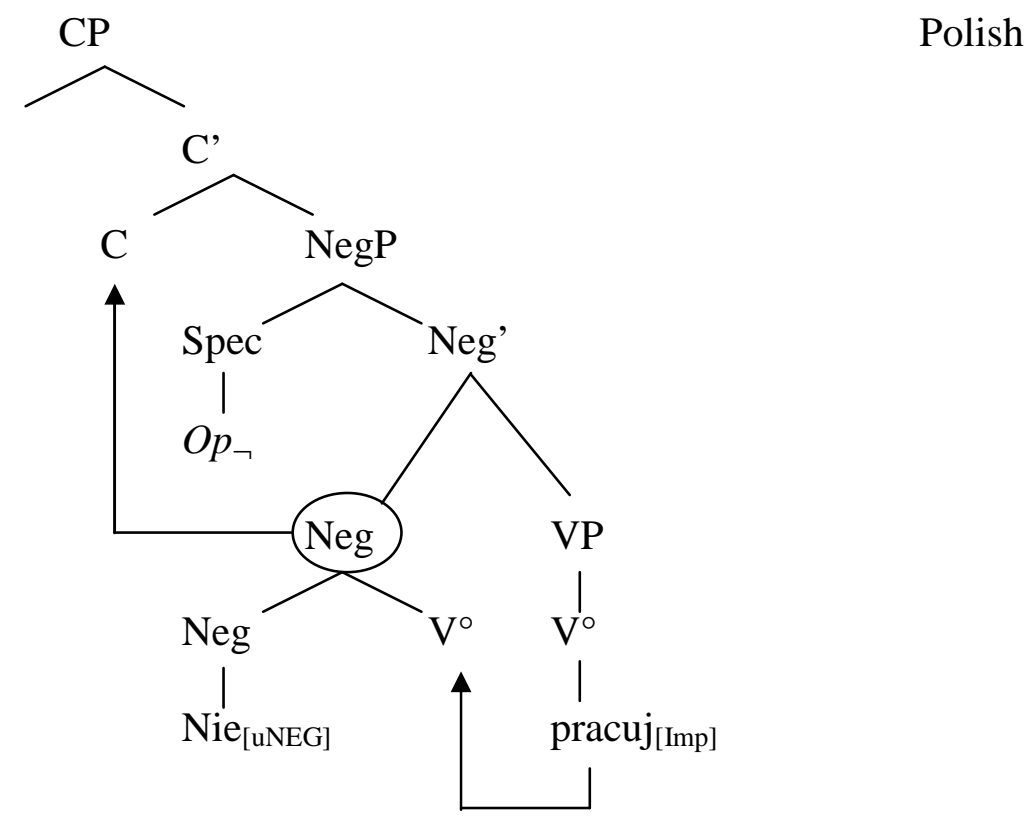


(24)



\subsection{Class III languages}

The third class of languages under discussion consists of (amongst others) Romanian, Hungarian, Greek and Hebrew. These languages also exhibit $\mathrm{X}^{\circ}$ negative markers carrying [uNEG] features, but contrary to Class II languages they ban TNIs. As has been discussed in the beginning of this section, movement of $\mathrm{V}_{\text {imp }}$ to $\mathrm{C}^{\circ}$ obeys the HMC. Consequently, if a negative marker is base-generated in $\mathrm{Neg}^{\circ}, \mathrm{V}_{\text {imp }}$ must attach to it, otherwise the derivation crashes. However, it depends on the phonological properties of a negative marker whether it allows this kind of clitisation. It could very well be that this negative marker cannot be

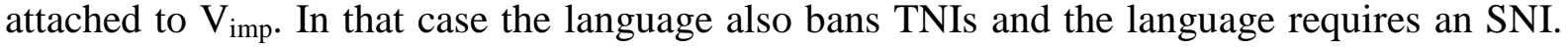
This possibility is born out by the typology presented in (20).

A result of the fact that some languages generally block verbal movement to a higher position than $\mathrm{Neg}^{\circ}$ is that alternative suppletive strategies have to be followed (subjunctives for instance generally have to raise to $\mathrm{C}^{\circ}$, too). One strategy can be to use a different negative marker for negative imperatives. ${ }^{10}$ This is the case for instance in Hungarian, where TNIs (using the regular negative marker nem) are ruled out, but where the (phonologically weaker) negative marker $n e$ is used as a suppletive marker. This negative marker allows for attachment to $\mathrm{V}_{\text {imp }}$ (either in $\mathrm{Neg}^{\circ}$ or $\mathrm{V}^{\circ}$ ) and, carrying [uNEG], it can yield negative imperatives. This is illustrated below.
a. *Nem olvass!
Neg read.IMP
'Don't read!'
b. Ne olvass!
Neg read.IMP
'Don't read!'

If $n e$ is base-generated in $\mathrm{V}$, the derivation is equivalent to the one for Czech in (24), if $n e$ is base-generated in $\mathrm{Neg}^{\circ}$ a structure equivalent to (23) represents the correct structure.

Note that, if a second negative marker is used for negative imperatives, this distinction will be grammaticalised. It becomes part of the featural equipment of these negative markers in which contexts they are allowed to occur (mostly along the lines of mood ([ \pm irrealis] for instance), as illustrated by Saddock and Zwicky (1985)). A phonologically distinct negative

\footnotetext{
${ }^{10}$ Van den Auwera (2005) shows that this is one of the strategies attested most often.
} 
marker has such a feature bundle that it only occurs in those contexts where it is allowed, and the default negative marker will then be reanalysed such that it is assigned a feature bundle that ensures that it is mutually exclusive with respect to the other negative marker. As a result of this grammaticalisation both negative markers can be phonologically weakened in due course without changing the language with respect to the status of TNIs, although the original motivation for the second negative marker was the fact that the phonological strength of the


large number of Strict NC languages (with negative head markers) still ban TNIs.

\subsection{Class IV languages}

It follows too that if a negative marker has phrasal rather than head status, TNIs are accepted. Regardless of the position of the negative marker, it cannot block movement of $\mathrm{V}_{\text {imp }}$ to $\mathrm{C}^{\circ}$. Hence $O p_{\text {IMP }}$ can always take scope from $\mathrm{C}^{\circ}$ and all scopal requirements are met. In Zeijlstra (2004) it has been argued that the position of the negative marker in Dutch is a vP adjunct position. The structure of a TNI in Dutch would then be like (26).

[CP $\operatorname{slaap}_{[I m p] i}\left[\mathrm{vP}\right.$ niet $\left.\mathrm{t}_{\mathrm{j}}\right]$ ]

Dutch

Note that from this analysis typological generalisation G2 follows immediately. If in a particular language there is no negative marker $\mathrm{X}^{\circ}$ available, movement of $\mathrm{V}_{\text {imp }}$ to $\mathrm{C}^{\circ}$ can never be blocked. Consequently, all languages that ban TNIs exhibit an overt negative marker $\mathrm{X}^{\circ}$.

\subsection{Class V languages}

Class V languages finally are NC languages without a negative head marker, such as Bavarian Quebecois and Yiddish. Given the explanation for G2, it is not expected that TNIs are banned in these languages. The only difference between these languages and Class IV languages is that the negative marker in these languages does not carry an [iNEG] feature. ${ }^{11}$ Hence, an abstract negative operator $O p_{\neg}$ needs to be included. This could either be (depending on one's syntactic views) in a (higher) VP adjunct position or in Spec,NegP. Whatever structure is adopted (the representation in (27) is just an example of the two possible structures), verbal movement to $\mathrm{C}^{\circ}$ cannot be blocked and therefore TNIs are allowed.

$$
\begin{aligned}
& \text { Kuk nit! } \\
& \text { Look NEG } \\
& \text { 'Don't look!' } \\
& \text { [CP Kuk }{ }_{[I m p] i}\left[{ }_{\text {NegP/VP }} O p_{\neg}\left[\mathrm{NegP} / \mathrm{VP} \text { nit }\left[\mathrm{vP}_{\mathrm{i}} \mathrm{t}_{\mathrm{i}}\right]\right]\right]
\end{aligned}
$$

Yiddish

\subsection{Concluding remarks}

It follows that the three assumptions that I presented in the beginning of this section $\left(O p_{\text {IMP }}\right.$ takes scope from $\mathrm{C}^{\circ}, O p_{\text {IMP }}$ may not be c-commanded by a negative operator and the HMC) predict that in some languages TNIs are excluded. Moreover the analysis based on these assumptions predicts the typological generalisations G1 and G2.

\footnotetext{
${ }^{11}$ This follows from the observation that in languages such as Yiddish a negative marker may occur both the left and to the right of an n-word, and exhibit NC.
} 


\section{Further evidence: diachronic change}

In Non-strict NC languages with a negative marker $\mathrm{X}^{\circ}$ (that must carry [iNEG]) TNIs must be banned. This holds for instance for Italian. However, it is known that Old Italian allowed TNIs (as pointed out by Zanuttini (1997) and shown in (28)). The analysis presented above predicts that is impossible that the negative marker non in Italian, which is a syntactic head, carries a feature [iNEG] but constitutes TNIs. It could however be that Old Italian non carried [uNEG] and thus the prediction is that Old Italian cannot have been a Non-strict NC language. This prediction is born out. Old Italian was a Strict NC language, with a negative marker non that carried a feature [uNEG], as shown in (29).

a. $\quad N i$ ti tormenta di questo! $!^{12}$

Old Italian

NEG yourself torment.2SG.IMP of this

'Don't torment yourself with this'

b. *Non telefona a Gianni!

Cont. Italian

NEG call.2SG.IMP to Gianni

'Don't call Gianni'

a. $\quad$ Mai nessuno oma non si piò guarare ${ }^{13}$

Old Italian

$\mathrm{N}$-ever n-even-one man NEG himself can protect

'Nobody can ever protect himself'

b. $\quad$ Nessuno (*non) ha detto niente

Cont. Italian

$\mathrm{N}$-body neg has said $\mathrm{n}$-thing

'Nobody said anything'

Apparently Italian developed from a Strict NC language into a Non-strict NC language. Since in Old Italian TNIs were allowed, the change from Strict NC into Non-strict NC must have caused the ban on TNIs. Similar observations can be made for the development of Portuguese that used to be a Strict NC language that allowed TNIs and transformed into a Non-strict NC language that bans TNIs. See Zeijlstra (2006) for a more detailed analysis of the development of Romance languages with respect to NC. The analysis presented above predicts that the diachronic developments with respect to the acceptance of TNIs and the kind of NC that a language exhibits are related. The fact that this prediction is born out further supports this analysis.

\section{Conclusions}

In this paper I analyse the ban on TNIs as a result of three principles: (i) the fact that $O p_{\text {IMP }}$ universally takes scope from $\mathrm{C}^{\circ}$; (ii) the fact that $O p_{\text {IMP }}$ may not be c-commanded by a negative operator and (iii) the HMC (an instance of Relativized Minimality). It follows that if a negative marker is a syntactic head and carries an [iNEG] feature, $V_{\text {imp }}$ may not move across $\mathrm{Neg}^{\circ}$, but must attach to it. Hence, the [IMP] feature remains under the scope of negation and the TNI is ruled out.

From this analysis the typological generalisations $\mathbf{G 1}$ and $\mathbf{G 2}$ can also be derived. G1 follows, since (as explained above) every Non-strict NC language with a negative marker $\mathrm{X}^{\circ}$ this negative marker must carry [iNEG] and thus TNIs are ruled out. G2 follows because of the $\mathrm{HMC}$. If a language does not exhibit a negative marker $\mathrm{Neg}^{\circ}$, this marker can never block verbal movement to $\mathrm{C}^{\circ}$ and TNIs must be allowed.

\footnotetext{
${ }^{12}$ Zanuttini (1997).

${ }^{13}$ Martins (2000): 194
} 
Finally, it follows that diachronic developments with respect to the kind of NC (Strict/Nonstrict) that a language exhibits may influence a language's ban on TNIs. It is shown for Italian that this prediction is indeed correct.

\section{References}

Adger, D.: 2003, Core Syntax: a minimalist approach, Oxford: Oxford University Press.

Brown, S.: 1999, The Syntax of Negation in Russian, Stanford: CSLI Publications.

Chomsky, N.: 2001, Derivation by Phase, in M. Kenstowicz (ed.), Ken Hale: a Life in Language, MIT Press, pp. 1-52.

Frege, G.: 1892, Über Sinn und Bedeutung, Zeitschrift für Philosophie und philosophische Kritik 100: 25-50. Translated as: On Sinn and Bedeutung, in M. Beaney (ed): 1997, The Frege Reader, Blackwell Publishers.pp. 151-171.

Giannakidou, A.: 2000, Negative ... Concord?, Natural Language and Linguistic Theory 18, 457-523.

Giannakidou, A.: 2002, N-words and Negative Concord, Ms. University of Chicago.

Giannakidou, A. 2005: The landscape of EVEN items, Ms. University of Chicago.

Haegeman, L.: 1995, The syntax of negation, Cambridge Studies in Linguistics 75, Cambridge: Cambridge University Press.

Han, C.: 2001, Force, negation and imperatives, The Linguistic Review 18, 289-325.

Haraiwa, K.: 2001, Multiple Agreement and the Defective Interventione Effect, Ms MIT.

Haraiwa, K.: 2005, Dimensions in Syntax, Ms. University of Tokyo.

Herburger, E.: 2001, The negative concord puzzle revisited, Natural Language Semantics 9, 289-333.

Jespersen, O.: 1917, Negation in English and other Languages, Copenhagen: A.F. Høst.

Ladusaw, W. A.: 1992, Expressing negation. In C. Barker and D. Dowty (eds), SALT II, Cornell Linguistic Circle.

Laka, I.: 1990, Negation in Syntax: on the Nature of Functional Categories and Projections. PhD dissertation, MIT.

Lee, C.: 1988, Speech act terms and mood indicators (in Korean), Acta Linguistica Hungarica 38, $127-41$.

Martins, A.M.: 2000, Polarity Items in Romance: Underspecification and Lexical Change, in S. Pintzuk, G. Tsoulas, and A. Warner (eds), Diachronic Syntax: Models and Mechanisms, Oxford University Press.

Merchant, J.: 2001a, The syntax of silence, Oxford: Oxford University Press.

Merchant, J.: 2001b, Why no(t), Ms. University of Chicago. 
Rivero, M.L.: 1994, Negation, imperatives and Wackernagel effects, Rivista di Linguistica 6.

Rivero, M.L. \& Terzi, A.: 1995, Imperatives, V-movement, and Logical Mood, Journal of linguistics 31, 301-332.

Rizzi, L. :1982. Issues in Italian Syntax, Dordrecht /Cinnaminson, NJ: Foris Publications.

Rizzi, L.: 1989, Relativised Minimality, Cambridge, MA: The MIT Press.

Rowlett, P.: 1998, Sentential Negation in French, New York/Oxford: Oxford University Press.

Sadock, J. and Zwicky, A.: 1985, Speech act distinctions in syntax, in T. Shopen (ed), Language typologie and syntactic description, Cambridge University Press, pp. 155-96.

Travis, L.: 1984, Parameters and Effects of Word Order Variation, PhD Dissertation, MIT.

Ura, H.: 1996, Multiple Feature-Checking: A Theory of Grammatical Function Splitting, PhD Dissertation, MIT.

Van den Auwera, J.: 2005, Why languages prefer prohibitives, Valencia: Studea Linguistica Europea.

Van der Wouden, T.: 1994, Negative Contexts, PhD Dissertation, University of Groningen.

Watanabe, A.: 2004, The Genesis of Negative Concord, Linguistic Inquiry 35, 559-612.

Zanuttini, R.: 1994. Speculations on negative imperatives, Rivista di linguistica 6, 119-142.

Zanuttini, R.: 1997, Negation and clausal structure. A Comparative Study of Romance languages. Oxford studies in comparative syntax, New York, Oxford: Oxford University Press.

Zanuttini, R.: 2001, Sentential Negation, in M. Baltin and C. Collins (eds), The Handbook of Contemporary Syntactic Theory, Blackwell, pp. 511-535.

Zeijlstra, H.: 2004, Sentential negation and Negative Concord. PhD Dissertation, University of Amsterdam.

Zeijlstra, H.: 2006, How semantic dictates the syntactic vocabulary, in C. Ebert and C. Endriss (eds), Proceedings of Sinn \& Bedeutung 10, ZAS. 